\title{
"Skyscape Archaeology Keynote Lectures", Organised by the Sophia Centre, University of Wales Trinity Saint David, Spring 2020
}

\section{Steven R. Gullberg}

Director for Archaeoastronomy and Astronomy in Culture, University of Oklahoma, Norman, Oklahoma, USA srgullberg@ou.edu

Astronomy in culture is an enthralling topic that fascinates many. Conferences, such as those organised by the European Society of Astronomy in Culture (SEAC), are normally held every year to share research and ideas, but due to the pandemic, this year has been different. Dr Nicholas Campion and the Sophia Centre have performed a public service by presenting a series of virtual lectures on various aspects of cultural astronomy. While such work could not be shared in person, offering lectures in this manner means that the talks may have reached an even wider global audience.

The series originally advertised eight lectures spread across four two-hour sessions over four weeks, but because of their popularity an extra session was added at the end, bringing the total to ten presentations. The two hours allocated for each session worked very well, as it allowed for questions.

The first session, on 12th May, began with an introduction by Dr Campion that outlined the lecture series, skyscape archaeology and related educational opportunities in the MA Cultural Astronomy and Astrology programme at the University of Wales Trinity Saint David. The first main speaker, Prof. J. McKim Malville, is among the world's foremost scholars in archaeoastronomy, and he has been my personal mentor since he supervised my doctoral research on Inca astronomy in the Andes mountains of Peru. It was at that time that he first emphasised to me that archaeoastronomical data must be placed into cultural context. This essential concept has continued to evolve in importance over the years since and was certainly at the centre of the important work that was presented in these virtual sessions on skyscape archaeology. 
Prof. Malville began the series with "Entangling the Cosmos: The Astronomy of the Ancestral Pueblos, I: The Great Houses of Chaco Canyon: Palaces, Temples, and Living Beings", an account of the astronomy of the Puebloans at Chaco Canyon in New Mexico. He shared enlightening details about what is known at Chaco, long a primary area of his research, including the importance of rituals in relation to political power and the significance of the December solstice. He also reminded us that Puebloan astronomy developed independently - a question that should be considered as part of any cultural astronomical analysis.

In the following talk, "Building Baghdad", Dr Campion gave a historical account of the astrology of the ancient Babylonians. Something particularly interesting that he brought out is that we should forget the word "astrology" here and instead think of horoscopes as maps of the sky. The presentation included a thorough depiction of ancient astrology in this region, including its cultural context. However, a part of the talk that would likely be lost on many astronomers, archaeologists and anthropologists was with regard to examples he gave relating to the horoscopes in terms of contemporary astrology. Nevertheless, I enjoyed the lecture very much.

Prof. Malville followed up a week later on 19th May with "The Astronomy of the Ancestral Pueblos, II: The Cliff Dwellings of Mesa Verde: Powers of the Sun and Moon". He discussed the physical and cultural aspects of the site of Mesa Verde site in Colorado, including the Cliff Palace and the site's connection to the Twin War Gods. He also examined the significance of the Moon for the Pueblo people and discussed the 18.6-year major lunar standstill, though he later pointed out that in recurring only every 18.6 years this phenomenon may not have had a practical use. We also learned that the alignment to the June solstice sunrise at La Plata, Colorado, was similar to that at Pueblo Bonito in Chaco Canyon. He additionally stressed the importance of avoiding inferring random alignments.

The second lecture of the session, entitled "Clava Cairns: Holes in the Fabric of Space and Time, or Where the Heavens Come Down to Earth", was presented by Anna Estaroth, whose research in skyscape archaeology is conducted in the central highlands of Scotland. Her fascinating discussion dealt mainly with the cultural aspects of sites in this region. Her account covered local folkloric beliefs about the cairns being the scene of a full Moon fairy procession and the River Spey to the site's southeast being bloodthirsty and needing to take a human life each year. She also discussed her theory that the cairns were conceived as portals to another world. This was very much more on the anthropological rather than astronomical side of cultural astronomy, and it was a very informative lecture.

Dr Campion was again one of the speakers in the next session, on 26th May. His talk about "Calendar Buildings" presented an aspect of more recent cultural astronomy that has often been overlooked. There are numerous large buildings that include specific numbers of features that correspond to significant numbers for certain calendrical cycles. Examples from the seventeenth century include Knole House in Kent (1604), with 365 rooms and 52 staircases; Schloss Eggenberg in Graz (1666), with 365 exterior windows, 52 of which are in the 24 rooms of the piano nobile; and Scout Hall (1681) in Halifax, Yorkshire, which has 365 panes of glass, 52 doors and 12 bays. We learned that these buildings 
generally do not exhibit any astronomical orientations, but it appears structures with numbers of features related to these cycles was a recurring theme at this time.

After this, Tore Lomsdalen gave a solid overview of cultural astronomy in Malta, titled "Investigating Cosmology in Late Neolithic Malta". His research there has been extensive, and his knowledge is considerable. He discussed cosmology as a feature of all human societies, and very importantly that we must see the skies through the eyes of those who created particular sites, rather than imposing our own cultures. As an example of good practice, he mentioned Pauketat's (2018) approach, which supports combining astronomy research with archaeology. From his own research, Lomsdalen gave an example within the site of Mnajdra, discussing its entrances in relation to solar and stellar events and standstills of the Moon. This evolving work was an important addition to the lecture series.

Lionel Sims has given thought-provoking lectures for many years, and his contribution to the fourth session on 9th June was no exception. In "Through the Dark Vale: Interpreting the Stonehenge Palisade through Inter-Disciplinary Convergence", he described much of what he and David Fisher have been working on together for publication (Sims and Fisher 2020). There was a detailed description of the Palisade at Stonehenge and the many astronomical details that have been identified, including horizon alignments to the solstices and lunar standstills. It can sometimes be difficult to conceptualise Neolithic cosmology, but Sims importantly stressed that context for the builders was different from ours, as their perspective was one of living on a flat surface that was essentially at the centre of the cosmos. This description may still sound a bit Eurocentric at first, as although ancients in the third and second millennia $B C$ were observing recurring horizon events they were not necessarily thinking of the Earth in the same terms as the Greeks later would. He continued with a detailed description of his field work and its ontological context. His discussion about placing archaeoastronomical data into the context of the culture is part of what made this talk so valuable to those in attendance.

Dr Liz Henty has spent several years researching factors relating to skyscape archaeology. This, and her involvement as co-editor of the Journal of Skyscape Archaeology, has given her a firm foundation from which to deliver a most insightful account of "Skyscape Archaeology, Now and in the Future". Dr Henty and Dr Fabio Silva have made excellent progress toward a much-needed closer association between archaeoastronomy and archaeology, and in her presentation she related some of the history of attempts to arrive at an overarching term for the former, explaining that so far none has held universal sway. She asserted that the examination of astronomy in culture must be holistic and that ontology must be fully embraced by those involved in such research, in contrast to archaeoastronomers in the past who did not take this to heart. Fortunately, from what I now observe, the majority involved in current scholarly research understand the importance of placing data into its cultural context and the efforts of herself and Silva, as described in her lecture, have encouraged this even further. After discussing the advances and successes that have taken place with archaeology in the UK, she then mentioned efforts to promote the subject in other parts of Europe as well. She stressed the importance of education and training for researchers (in archaeology degree programmes and sources), of attracting new researchers to the field and of increasing the amount of scholarly 
publications. Different approaches to advancing archaeoastronomy may be needed in different parts of the world, but what has been achieved in the UK as shown in this lecture is quite noteworthy.

The "encore session" of the lecture series was held two weeks later, on 23rd June, and the first of the two additional talks was once more presented by Prof. Malville. In "Sacred Landscapes, Entanglements, Bundling, and Knots in Space-Time", he began by underlining his assertion that archaeoastronomy must be advanced with colleagues in archaeology. In this regard he introduced Pauketat's (2018) thoughts about the "bundling" of things important in a culture, moving on to the bundling of bodies, souls and objects in certain Native American cultures, and he also offered examples from other parts of the world. This was a concept of which many who were in attendance were likely previously unaware. As regards his own opinion on archaeoastronomy, Malville drew much upon his background as an astrophysicist in relating various archaeoastronomical concepts to principles of astrophysics. He rightly emphasised that archaeoastronomy, cultural astronomy and skyscape archaeology are about people, and not simply aligned stones, and he also drew attention to research shortcomings of the past.

Finally, Dr Silva introduced a most intriguing concept in "Passage Mounds: Symbolism, Skyscape, and Ritual Sodalities". First, however, he began with a discussion of some of the astronomy known at sites in Britain and Ireland such as Newgrange, Knowth, Maeshowe, Barclodiad y Gawres and Bryn Celli Ddu. He then took up the theme of bundles, as previously introduced by Malville, discussing aspects of cosmology at these sites and unwrapping cultural bundles that might be found there. He posed an intriguing question: to what purposes could passages serve in addition to allowing access? After these preliminary thoughts, his lecture segued into a discussion of intriguing ideas regarding secret societies and ritual sodalities, for example that certain passage mounds may have been constructed by prehistoric secret societies and that these were non-kinship societies based upon rituals for organisation, control and power. He suggested that these concepts might help to bring various hypotheses into a single framework. This is an expansion of the ideas found in Brian Hayden's The Power of Ritual in Prehistory (2018). Silva discussed fundamental societal aspects such as special structures, remote locations, ritual paraphernalia, sophisticated art, power animal iconographs and special burial for high-ranking members. An example Hayden used was that human burials in passage mounds were in close proximity to these secret societies and not to kin, concluding that such secret societies bringing together their shared ritual language was a search for power. This was a most intriguing discussion on a topic that definitely warrants further examination.

The timing of these virtual lectures was excellent, as they kept discussion about skyscape archaeology going even as onsite archaeoastronomical conferences were being cancelled. The topics selected for presentation represented an appropriate cross-section to give a broad perspective on important issues. The speakers collectively delivered a comprehensive overview of cultural astronomy in a manner that speaks highly of how this series was organised by the Sophia Centre. Malville gave three varied talks that expressed his extensive knowledge of archaeoastronomy and astronomy in culture as 
well as introducing the concept of bundling. He emphasised the recurring theme in these talks, which is that any astronomical data collected must be placed into its cultural context. The importance of cultural context was also stressed by several other speakers. Campion's two lectures, respectively on Babylonian astrology and calendar buildings, were enlightening and fascinating, as was Estaroth's presentation on a lesser known topic regarding the Clava Cairns in Scotland. I have heard Lomsdalen speak about archaeoastronomy in Malta before, and he did a terrific job here once again. Sims delivered another outstanding presentation regarding one of the many aspects of Stonehenge, where he has spent so many years conducting research. Henty demonstrated her exhaustive research and attention to detail as she thoroughly discussed various aspects of skyscape archaeology and the importance of engaging more archaeologists in astronomically related research, as this can help them learn more about the cultures that are the focus of their field studies. And finally, Silva gave an informative tour of some of the astronomically aligned sites in the UK and Ireland before he moved on to introduce and expand upon the intriguing concept that ancient secret societies that crossed kin boundaries were formed in an effort to consolidate power and control. Developing stronger ties with archaeology is very important, and Henty and Silva have done great work in this regard. Overall, this was an important lecture series that took place at a critical time. The information presented by each speaker was insightful and thought-provoking. The Sophia Centre can be applauded for this contribution!

\section{References}

Hayden, B. 2018. The Power of Ritual in Prehistory: Secret Societies and Origins of Social Complexity. New York: Cambridge University Press. https://doi.org/10.1017/9781108572071

Pauketat, T. R. 2018. An Archaeology of the Cosmos: Rethinking Agency and Religion in Ancient America. New York: Routledge.

Sims, L. and D. Fisher. 2020. "Through the Dark Vale: Interpreting the Stonehenge Palisade through Interdisciplinary Convergence". Journal of Skyscape Archaeology 6 (1): 5-29. https://doi.org/10.1558/jsa.38690 